Pregledni znanstveni rad DOI: $10.17234 /$ Croatica.42.21 UDK: 81'38:81'42Pranjković, I. Primljen: 13. XI. 2017.

Prihvaćen: 12. I. 2018.

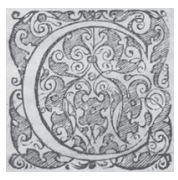

\title{
STILISTIKA GOVORNIKA I SUGOVORNIKA
}

\author{
Marina Katnić-Bakaršić \\ Filozofski fakultet u Sarajevu, Univerzitet u Sarajevu \\ Odsjek za slavenske jezike i književnosti \\ marinakatnic@bih.net.ba
}

Rad predstavlja intertekstualni dijalog s tekstom Gramatika govornika i sugovornika Ive Pranjkovića. Razmatraju se neka pitanja koja su ključna za stilistiku govornika i sugovornika: uloga deikse, stilogena upotreba ličnih zamjenica i njihova uloga s aspekta kritičke stilistike, transpozicije lica i njihova potencijalna figurativnost, tuđi govor, pitanje adresata književnoga djela i posebno stilistička proučavanja dramskoga dijaloga. Pokazuje se da gramatičke kategorije vezane za govornika i sugovornika zahvaljujući deiksi imaju važan stilski potencijal i nezaobilazne su u različitim suvremenim stilističkim pristupima.

Ključne riječi: deiksa, govornik, sugovornik, stilistika, lične zamjenice

\section{UMJESTO UVODA: OD GRAMATIKE DO STILISTIKE PRANJKOVIĆU U ČAST}

Naslov ovoga rada, iako na prvi pogled neupućenom promatraču stilski nezanimljiv, zapravo je parafraza naslova teksta Gramatika govornika $i$ sugovornika Ive Pranjkovića (2013: 9-25), odnosno uvod u intertekstualni dijalog s tim tekstom. Kao što se u poststrukturalizmu naglašava, ne postoji tekst sam za sebe, a svaki tekst uvijek iščitava drugi. U tom je smislu i ovaj 
tekst pisan s punom sviješću o dijalogu s Pranjkovićevim tekstom, ali i o dijalogu s drugim njegovim gramatičkim radovima koji se često otvaraju prema propitivanju komunikacijskoga čina. Osim toga sam Ivo Pranjković u mnogim svojim drugim radovima bavi se pitanjima stila i posebno pitanjima suodnosa gramatike i stilistike - dovoljno je spomenuti samo poglavlje Gramatika i stilistika u knjizi Gramatika u riječima i riječi u gramatici, u kojem se postavljaju pitanja "odnosa između gramatike i stilistike, i o granicama između jedne i druge, i o ingerencijama jedne u odnosu na drugu" (Pranjković 2016: 328). Ne treba zaboraviti ni druge njegove stilističke radove koji pokazuju da se o Pranjkoviću s razlogom može govoriti i kao o stilističaru (Katnić-Bakaršić, Požgaj Hadži 2010: 85-92).

Rad stoga prati postupak što ga u spomenutom tekstu primjenjuje sam Ivo Pranjković kada daje pregled različitih gramatičkih kategorija i pojavnosti vezanih za govornika i sugovornika, te će u daljem tekstu biti riječi o nekim aspektima koji su ključni za stilistiku govornika i sugovornika. Prije svega tu mislim na pitanja koja su nezaobilazna u suvremenoj stilistici - stilistička proučavanja dijaloga, posebno dramskoga ili općenito literarnoga, pitanja sinonimije, odnosno transpozicije lica i vremena kao glagolskih kategorija, pri čemu se te transpozicije proučavaju i kao stilske figure, pitanja stilski markirane upotrebe ličnih zamjenica, posebno njihove uloge u kreiranju odnosa moći, čime se bavi kritička stilistika, ali i pitanja što već zadiru u književnu stilistiku, poput pitanja adresata književnoga djela ili semantičke strukture poetskoga teksta. Ovome se može dodati i to da se $u$ funkcionalnoj stilistici zastupljenost/nezastupljenost oblika prvog i drugog lica smatrala važnim kriterijem za razlikovanje pojedinih funkcionalnih stilova, podstilova ili žanrova. Čak i danas kritička stilistika osobitu pozornost poklanja odabiru forme lica u nekim tipovima diskursa, posebno u akademskom diskursu, pa upotrebu bezličnih formi i/ili trećeg lica, odnosno prvoga lica množine kao tzv. "autorskoga mi" ili pak prvoga lica jednine kao svojevrsne emancipacije vlastitoga "ja" interpretira kao izraz određene ideologije i različito shvaćenih odnosa moći u tom diskursu (o tome v. Katnić-Bakaršić 2012: 70-71). Kao što se vidi, gramatičke kategorije vezane za govornika i sugovornika nose važan stilski potencijal i zastupljene su u različitim stilističkim pristupima. Ovo nije slučajno kada se uzme u obzir kako su u većini jezika posebno značajne one gramatičke pojavnosti "koje dolaze do izražaja u govornom činu ili su vezane za govornika odnosno za sugovornika" (Pranjković 2013: 9). Za Borisa Uspenskog, koji proučavanje gramatike povezuje sa proučavanjem stilistike, semiotike i kulture uopće, "govorni čin je polazište za formiranje 
predstave o objektivnoj stvarnosti, koja postoji nezavisno od individualnog iskustva" (Uspenski 2012: 37).

\section{ULOGA DEIKSE U SUVREMENOJ STILISTICI}

Bilo da se o govorniku i sugovorniku govori s gramatičkog ili stilističkog aspekta, neophodno je početi od deikse koja i omogućava ostvarivanje komunikacije (Uspenski 2012: 12). U tom je smislu ključna uloga deiktičkih elemenata u jeziku, prije svega ličnih zamjenica, zatim ličnih glagolskih oblika, ali i drugih elemenata - čestica, priloga, uzvika i sl., koji također mogu dobiti komunikacijsku ulogu (Pranjković 2013: 9-25). Za suvremenu stilistiku važno je i to što se osnovnom modelu deikse, koji uključuje personalnu, temporalnu i lokalnu deiksu, dodaje i socijalna u koju spadaju oslovljavanje sugovornika i načini obraćanja čija je uloga ukazati na socijalnu distancu ili bliskost između govornika i sugovornika, odnosno pokazati njihove hijerarhijske odnose (Jeffries 2009: 149).

\subsection{Lične zamjenice i kategorija lica u stilistici}

Pođimo prije svega od ličnih zamjenica koje se u stilistici mogu promatrati na dva plana - na planu njihove ekspresivnosti i na planu sinonimije, odnosno transpozicije, u čemu su tijesno povezane s glagolskim licima i njihovom sinonimijom. U retorici i stilistici govori se u tom smislu o enalagama lica (Zima 1988, Bagić 2012: 96-98), koje uključuju cijeli niz mogućih manje ili više stilogenih zamjena lica. U to se ubrajaju npr. zamjena zamjenice ja i prvoga lica jednine zamjenicom mi, odnosno prvim licem množine s različitim značenjem (autorsko mi ili mi skromnosti, kraljevsko mi, tzv. "seosko" $m i$ ); upotreba zamjenice $m i$ u značenju ti/vi ("liječničko" ili "empatijsko" $m i$ - Kako smo danas?), upotreba bezličnih umjesto ličnih formi i drugo.

U poeziji ovakve enalage počinju dobivati izrazito "artistične" oblike, kao u Pupačićevoj pjesmi Tri moja brata, koju kao primjer enalage lica i broja navodi Krešimir Bagić (Kad sam bio tri moja brata i ja/ kad sam bio četvorica nas) (2012: 98). Takvi primjeri pokazuju i snažnu ekspresivnost enalaga i izrazito su individualizirani, za razliku od uobičajenih slučajeva sinonimije lica koji se mogu proučavati i u gramatici, a ne samo u stilistici. Funkcionalnu stilistiku uvijek će zanimati distribucija ovih transpozicija 
u različitim funkcionalnim stilovima, dok će stilistika literarnog diskursa uvijek promatrati njihovu ekspresivnost i stilogenost u svakom konkretnom slučaju. Enalage lica u suvremenoj retorici i stilistici ponekad se i definiraju kao figure povezane s pošiljateljem i primateljem informacije (drugim riječima, s govornikom i sugovornikom), pri čemu se također naglašava da sam komunikacijski čin uvjetuje njihove privilegirane i simetrične pozicije (Dubois i sur. 1988: 281).

Kada je riječ o glagolskim oblicima i kategoriji lica, stilistiku sugovornika posebno zanima potencijal imperativa. Ovo nije nimalo slučajno ako se zna da je "imperativ(nost) u najužem smislu riječi kategorija drugoga lica" (Pranjković 2013: 14). S aspekta pragmatičke stilistike imperativ je zanimljiv kao govorni čin koji ima dominantnu ulogu direktiva i njegova zamjena indirektnim činom bitno utječe na stil teksta. U kritičkoj stilistici upotreba imperativa vezana je za dominantnoga govornika, dok je sugovornik (sugovornici) po pravilu (ali ne uvijek) u subordiniranoj poziciji. Kritička stilistika stoga proučava ulogu imperativa s obzirom na odnose moći u različitim diskursnim tipovima ili žanrovima.

\subsection{Lične zamjenice od znakova moći do semantičke osovine lirske pjesme}

Lične zamjenice imaju posebno mjesto u kritičkoj stilistici u kojoj se pored suodnosa govornika i sugovornika posebno relevantnim smatra suodnos nekoga $m i$ i onih adresata koji se time svrstavaju u vi, a pogotovo onih koji postaju oni. Suodnos Mi - Oni iznimno je važan, pri čemu se uvijek razlikuje inkluzivno i ekskluzivno $M i$, gdje je ovo prvo signal solidarnosti, bliskosti $(\mathrm{Ja}+\mathrm{Ti} / \mathrm{Vi})$, a drugo signal moći i snage broja ( $\mathrm{Ja}+$ "moji ljudi", meni bliski; $V i$ niste uključeni u to). "Isključivanje Drugoga jedna je od osnovnih strategija za (nelegitimno) očuvanje postojećih odnosa moći" (Katnić-Bakaršić 2012: 55). Nije slučajno što se u proučavanju političkog i medijskog diskursa upravo upotreba ovih zamjenica, odnosno pozicioniranje govornika i sugovornika, kao i pozicioniranje onih koji ne sudjeluju u komunikacijskom činu i označeni su kao Oni, smatra jednim od osnovnih pokazatelja nejednakih odnosa moći s aspekta kritičke diskursne analize i kritičke stilistike.

Drugi aspekt ličnih zamjenica vezan je za stilističko proučavanje poezije. Naime u stilistici se pokazuje da je semantička osovina lirske pjesme često suodnos $j a-t i$, odnosno direktan suodnos govornika i adresata. U skladu $\mathrm{s}$ tim onda se i prostorne i vremenske opozicije uspostavljaju u odnosu na 
govornika (gore - dolje, desno - lijevo, sada-onda/tada). Čak i tamo gdje na prvi pogled nema relacije $j a-t i$, lirska pjesma pomoću nekih drugih elemenata implicira postojanje upravo suodnosa govornika i sugovornika. U poznatoj Cesarićevoj pjesmi Voćka poslije kiše za uspostavljanje takvoga suodnosa (Gle malu voćku poslije kiše, / puna je kapi pa ih njiše) dovoljna je čestica gle, za koju i Pranjković navodi da je "izrazito komunikacijske naravi" i samim tim deiktična (Pranjković 2013: 22). Iako se govornik i sugovornik nigdje izrijekom ne spominju, ova je čestica konstituirala njihove pozicije, što je svakako relevantno za stilističku interpretaciju pjesme u cjelini.

Pranjković (2013: 15) navodi da za gramatiku govornika i sugovornika važnu ulogu ima i vokativ, odnosno obraćanje; direktna povezanost obraćanja sa stilistikom sugovornika također je neupitna. Dovoljno je samo spomenuti persuazivni potencijal obraćanja u oratorskom, političkom ili reklamnom diskursu. Oslovljavanje i obraćanje sugovorniku također su svojevrsni signali socijalne deikse, o kojoj je ranije bilo riječi, te se oni u kritičkoj stilistici neizostavno analiziraju u različitim diskursnim tipovima ili žanrovima, ali i u svakoj konkrentnoj upotrebi. Oslovljavanje i forma obraćanja pokazuju odnose moći u diskursu (npr. političkom, dramskom ili svakodnevnom). Kada je riječ o literarnom diskursu, ne treba zaboraviti da se za lirsku poeziju karakterističnom i inače smatra figura apostrofe, pod kojom se podrazumijeva "izravno obraćanje odsutnoj ili iščezloj osobi, životinji, biljci, nadnaravnoj sili, ideji, konceptu, prirodnoj pojavi itd." (Bagić 2012: 64). Apostrofa je izazvala brojne diskusije i polemike u znanosti o književnosti od Paula de Mana naovamo, ali u kontekstu ovoga rada i stilističkoga pristupa ona je značajna zbog toga što uvijek bar implicitno uspostavlja osovinu $j a-t i$, odnosno poziciju govornika i sugovornika. Pored toga ona ponekad čak i bitno određuje stil nekog pjesnika; Bagić (2012: 65) navodi da ona može obilježiti "pojedini pjesnički koncept ili autorsku poetiku".

\section{STILISTIKA GOVORNIKA I SUGOVORNIKA: TUĐI GOVOR I TIPOVI PRIPOVIJEDANJA}

Za stilistiku govornika i sugovornika važno je i kako je realiziran tuđi govor. Ako pođemo od kritičke stilistike, vidjet ćemo da se prenošenje tuđeg govora, posebno u medijskom i političkom diskursu, smatra potencijalno manipulativnim jer uključuje ideološku poziciju onoga tko prenosi tuđi govor, samoga govornika i adresata (Jeffries 2009: 137-142). U stilistici 
literarnog diskursa tuđi govor potencijalno je uvijek stilogen. Nije nimalo slučajno što se posebno naglašava potencijal slobodnog neupravnog govora budući da je on "efikasniji i efektniji u prenošenju afektivnosti čak i od upravnog govora" (Vuletić 1976: 195). Stilogenost ovog oblika tuđeg govora počiva na dvojnosti - on je pisan u trećem licu, a prenosi afektivnost koja inače dolazi samo u upravnom govoru, odnosno u govoru u prvom licu. Ova dvojnost, odnosno svojevrsno istovremeno formalno prisustvo trećega lica i prikrivenog, a opet implicitno prisutnoga prvoga lica kao govornika, i uvjetuje stilogenost slobodnoga neupravnog govora.

Pored toga, kao što je poznato, i znanost o književnosti i naratologija i stilistika odavno razlikuju tipove pripovijedanja prema licu u kojem se pripovijeda. Najfrekventnije je pripovijedanje u prvom i u trećem licu, koje se povezuje s odnosom pripovjedača prema naslovljeniku pripovijedanja (Biti 1997: 321). Dok je treće lice shvaćeno kao ne-lice u benvenistovskoj koncepciji i stoga često implicira objektivnost, prvo lice odlikuje se većom subjektivnošću pa stoga pruža niz mogućnosti za stilističku interpretaciju. Međutim posebno su zanimljivi narativi u drugom licu. Ako prihvatimo mišljenje da je predstava o stvarnosti "po samoj svojoj suštini, egocentrična" jer se predstava o postojanju stvarnosti zasniva na predstavi o sopstvenom postojanju (Uspenski 2012: 37), onda je jasno da pripovijedanje u drugom licu narušava očekivanja, donosi nemir, ambigvitet, pa je zato i začudno. Pri tome su moguće različite varijante: jedna je kada je drugo lice upotrijebljeno u značenju prvoga ili u uopćenoličnom značenju - npr. u nekim dijelovima priče Eolska harfa Danila Kiša (Katnić-Bakaršić 2007: 334-335) ili u priči Plavo i zeleno Jurija Kazakova, a druga je varijanta kada se pripovijeda iz perspektive Drugoga, $\mathrm{tj}$. drugoga lica, koje postaje protagonist priče (jedan od prvih primjera je La Modification Michela Butora iz 1957, a kasnije je u ovom kontekstu posebno često spominjan roman Itala Calvina Ako jedne zimske noći neki putnik). Obje su varijante stilogene, ali na različite načine. U prvom slučaju govornik se distancira od vlastitog iskustva i predstavlja ga ili kao iskustvo drugoga ili pak kao općeljudsko iskustvo. U oba slučaja pripovijedanje postaje "alteregocentrično", kako to imenuje B. Z. Lobačev (1983), koji čak govori o većoj alteregocentričnosti nekih jezika u odnosu na druge polazeći od gramatičkih mogućnosti tih jezika; tako bi ruski bio više alteregocentričan od hrvatskoga, a pogotovo od francuskog jezika. Pisanje iz perspektive drugoga lica i uvođenje čitatelja kao protagonista učinilo je roman Itala Calvina Ako jedne zimske noći jedan putnik jednim od najčešće spominjanih postmodernih romana koji izigrava sve uobičajene fikcionalne 
postupke. Međutim ovdje Calvino uvodi Čitatelja kao lik, i taj lik nije ni stvarni ni implicitni čitatelj njegovog romana, a opet kod stvarnih čitatelja stvara ambigvitetnost: $\mathrm{s}$ jedne strane imaju dojam direktnog obraćanja njima, a s druge strane svjesni su da je Čitatelj tek lik u romanu.

Spomenut ću ovdje i postupak koji je postojao i u mnogim ranijim književnim pravcima, a to je direktno obraćanje (implicitnog ili stvarnog) autora/naratora čitatelju/-ima. Taj postupak bio je svojstven piscima raznih pravaca, npr. Gogolju kod koga se autor/narator u Mrtvim dušama ponekad obraća čitatelju, ali nalazimo ga i u suvremenoj prozi i prepoznajemo kao autoreferencijalnost. Tako npr. suvremeni autor Bekim Sejranović u romanu Tvoj sin Huckleberry Finn (Sarajevo, Buybook, 2015) cijelo pripovijedanje konstruira kao pripovijedanje čitatelju, odnosno čitateljima (u drugom licu množine) i time ostvaruje privid direktnog pripovijedanja i interakcije licem u lice, npr:

I tako, shvatili ste već, ovu priču pripovijeda mnogo tih 'ja' i svi oni vole da pretjeruju. Ono što dopre od vas, čitatelji moji dragi, ma tko bili, i ma koji od vaših 'ja' ovo čitao, nije ništa do sjene stvarnih događaja, eho jeke, fotografija reprodukcije umjetničke slike, snimka filma u kinu, 'playback' koncerta uživo. Ali opet je ponekad stvarnije i veće od "pravog” života (Sejranović 2015: 236).

Kao što vidimo, autor tematizira vlastito pripovijedanje i zbog toga je riječ o autoreferencijalnosti par excellence. Ovakva književna djela sadrže odnos govornik - sugovornik na više razina: prva je razina romana u cjelini, gdje se pripovjedač (stvarni ili implicitni autor) direktno obraća čitateljima (stvarnim ili implicitnim), dok je druga razina zastupljena u samom romanu, u dijalogu likova. Naravno da postoji cijeli niz drugih modela pripovijedanja koje ovakav rad ne može sve obuhvatiti, ali važno je uočiti stilski potencijal različitog prikazivanja suodnosa govornika i sugovornika u narativnim tekstovima.

\section{GOVORNIK I SUGOVORNIK U STILISTICI DRAMSKOGA DIJALOGA}

Dijalog je često shvaćen kao razmjena (informacija ili aktivnosti) pa se u skladu s tim načelom analizira i dramski i svaki drugi tip dijaloga, a ta je razmjena uvijek vezana za deiksu. I stilistička i semiotička tumačenja dramskog diskursa uvijek naglašavaju da deiksa omogućava dramskom dijalogu "aktivnu i dijalošku funkciju prije nego deskriptivnu i korsku; ona je 
situirana na izvorištima drame kao nužni uvjet nenarativnog oblika diskursa koji kreira svijet" (Elam 1980: 139). Dramski dijalog uvijek se realizira ovdje i sada, između nekoga ja i $t i$, pri čemu govornik uvijek pozicionira sve ostale elemente prema sebi (Herman 1995: 26-28; Katnić-Bakaršić 2013: 20-22). Gramatički se često "prostor konkretizira preko lica, odnosno preko pokaznih zamjenica, najizravnije pokaznim prilozima tipa ovdje, tu, ondje" (Pranjković 2013: 12). Tako ovdje dolazi kao proksimalni marker, shvaćen kao prostor u blizini govornika, dok je tamo distalni marker, koji označava udaljenost od njega; slično je i sa zamjenicama ovaj-onaj-taj, a i sa vremenskom deiksom i suodnosom sada-jučer - sutra, iduće godine, $u$ narednu srijedu itd., koje su svojevrsni šifteri i pune se sadržajem prema poziciji govornog lica. Govornikovo je tijelo "u deiktičkom kontekstu primarna tačka referencije za spacijalne dimenzije - kao što je lijevo, desno, naprijed, nazad, jer se one projiciraju od deiktičkog centra" (Herman 1995: 27). Upravo aspekt govornikovog tijela iznimno je važan za stilističku interpretaciju dramskog dijaloga jer ukazuje na to što govornik percipira kao blisko sebi, a što distancirano, i to ne samo u denotativnom nego i u metaforičkom smislu riječi. Budući da u dijalogu dolazi do stalnog alteriranja pozicija govornika i sugovornika, svi deiktički elementi uvijek su usklađeni s tim. Na osnovi ovoga mogu se donijeti dva važna zaključka: prvo, stilistička interpretacija dijaloga općenito nužno uključuje elemente deikse, i drugo, pored gramatičke i stilističke interpretacije nužna je i semiotička jer se deiksa uspostavlja i s obzirom na govornikovo tijelo.

\section{OD GRAMATIKE I STILISTIKE KA SEMIOTICI GOVORNIKA I SUGOVORNIKA}

Iako u radu nije u potpunosti ponovljena struktura Pranjkovićeva rada Gramatika govornika i sugovornika niti rad pretendira na iscrpnost popisa svih pitanja koja bi mogla zanimati stilistiku, pokušala sam pokazati koliko su i za stilistiku polazna točka upravo govornik i sugovornik kao dva ključna elementa svake verbalne interakcije. Ako bismo tražili razloge za brojna pitanja kojima se stilistika bavi, a vezana su za govornika i sugovornika, mogli bismo reći da se oni nalaze upravo u ulozi jezika kao sredstva za formiranje virtualne stvarnosti, pri čemu se to realizira pomoću deikse, odnosno deiktičkih elemenata, u kojima, kao što smo vidjeli, posebno mjesto zauzimaju lične zamjenice, ali i oblici glagolskoga lica (Uspenski 
2012: 9). Drugi važan zaključak jest taj da su gramatika i stilistika u ovome kontekstu mnogo više povezane nego što se to počesto misli i da različiti suvremeni stilistički pristupi nužno uključuju propitivanje pozicije govornika i sugovornika. Može se čak otvoriti još šira perspektiva, semiotička, koja bi bila posebno zanimljiva za kritičku ili multimodalnu stilistiku jer bi uključila vizualne, prostorne i druge neverbalne elemente koji su relevantni za govornika i sugovornika.

\section{LITERATURA}

Bagić, Krešimir. 2012. Rječnik stilskih figura. Zagreb: Školska knjiga.

Biti, Vladimir. 1997. Pojmovnik suvremene književne teorije. Zagreb: Matica hrvatska. Djubua, Žak i sur. 1986. Obščaja ritorika. Moskva: Progress.

Elam, Keir. 1980. The Semiotics of Theatre and Drama. London: Methuen.

Herman, Vimala. 1995. Dramatic Discourse. Dialogue as Interaction in Dramatic Plays. London, New York: Routledge.

Jeffries, Lesley. 2009. Critical Stylistics: the Power of English. Basingstoke: Palgrave Macmillan.

Katnić-Bakaršić, Marina. 2007. Stilistika. Drugo izdanje. Sarajevo: Tugra.

Katnić-Bakaršić, Marina; Požgaj Hadži, Vesna. 2010. Zapis o Ivi Pranjkoviću kao stilističaru. Jezična skladanja: Zbornik o šezdesetogodišnjici prof. dr. Ive Pranjkovića. [ur. Lada Badurina i Vine Mihaljević]. Zagreb: Udruga đaka Franjevačke klasične gimnazije Visoko - Zagreb. 85-92.

Katnić-Bakaršić, Marina. 2012. Između diskursa moći i moći diskursa. Zagreb: ZORO.

Katnić-Bakaršić, Marina. 2013. Stilistika dramskog diskursa. Drugo, izmijenjeno i dopunjeno izdanje. Sarajevo: University Press.

Lobačev, Boris. 1983. O kategorijah ego i al'teregocentrizma. Problemy strukturnoj lingvistiki 1981. Moskva: Nauka. 23-37.

Pranjković, Ivo. 2013. Gramatika govornika i sugovornika. Gramatička značenja. Zagreb: Matica hrvatska.

Pranjković, Ivo. 2016. Gramatika u riječima i riječi u gramatici. Zagreb: Matica hrvatska.

Uspenski, Boris A. 2012. Ego loquens. Jezik i komunikacioni prostor. Novi Sad: Akademska knjiga.

Vuletić, Branko. 1976. Fonetika književnosti. Zagreb: Sveučilišna naklada Liber.

Zima, Luka. 1988. Figure u našem narodnom pjesništvu. Zagreb: Globus. 


\section{SUMMARY}

\section{STYLISTICS OF THE SPEAKER AND HEARER}

The paper presents an intertextual dialogue with Ivo Pranjković's text Gramatika govornika $i$ sugovornika (Grammar of the speaker and hearer). Some issues that are crucial for stylistics of the speaker and hearer are addressed in this paper: the role of deixis, stylistic use of personal pronouns and their role from the perspective of critical stylistics, transpositions of person and their potential figurative use, presenting speech of the others, the issue of the addressee of a literary text and especially stylistic investigations of a dramatic dialogue. It has been shown that grammatical categories related to the speaker and hearer have important stylistic potential due to deixis and are unavoidable in different contemporary stylistic approaches.

Key words: deixis, speaker, hearer, stylistics, personal pronouns 